Original Article

\title{
Effect of increased functional residual capacity on the active range of thoracic axial rotation in healthy young men
}

\author{
Akira Kubo, RPT, PhD ${ }^{1)^{*}}$, Masahiro Ishizaka, RPT, PhD ${ }^{1)}$, Yoshiki Takeuchi, RPT ${ }^{1,2)}$, \\ KeIta Shimura, RPT, PhD ${ }^{3)}$ \\ 1) Department of Physical Therapy, Graduate School of Health and Welfare Science, International \\ University of Health and Welfare: 2600-1 Kitakanemaru, Ohtawara City, Tochigi 324-8501, Japan \\ 2) Shioya Hospital, International University of Health and Welfare, Japan \\ 3) Department of Physical Therapy, School of Health Sciences at Narita, International University of \\ Health and Welfare, Japan
}

\begin{abstract}
Purpose] To understand the effect of increased functional residual capacity (FRC) on the active range of thoracic axial rotation (AROTAR) in healthy young men. [Subjects and Methods] Thirty-nine right-handed healthy male volunteers (age $=20.1 \pm 1.6$ years) participated in this study. A standard plastic goniometer was used to measure the AROTAR in the supine position with both glenohumeral joints fully flexed. AROTAR was recorded at the resting expiration level (REL) and for 4 different FRC levels: 500, 1,000, 1,500, and 2,000 ml air inhaled at REL. FRC volumes and laterality were analyzed using a two-way repeated measure of ANOVA and post-hoc analysis. Relationships between the relative value (AROTAR for each increased FRC level / REL AROTAR $\times 100)$ and AROTAR for each increased FRC level were analyzed using Pearson's correlation coefficient. [Results] A significant main effect was found for only FRC factor. AROTAR had a positive moderate correlation with relative value. The correlation coefficient was higher than 0.5 for in 1500 and 2,000 ml. [Conclusion] An increase in FRC might decrease AROTAR and if the REL AROTAR is high, the decrease in AROTAR due to increased FRC is lesser. It is suggested that maintaining the thoracic mobility could minimize a COPD patient's AROTAR limitation and maintain physical ability.

Key words: Functional residual capacity, Range of thoracic axial rotation, COPD
\end{abstract}

(This article was submitted Oct. 6, 2017, and was accepted Nov. 16, 2017)

\section{INTRODUCTION}

Chronic Obstructive Pulmonary Disease (COPD) is a major public health problem. By 2020, COPD is predicted to be the third $^{1)}$ and fifth ${ }^{2)}$ leading causes of death in the world. Poor thoracic mobility is one of the major disabilities in patients with COPD. The disease severely affects their ability to perform activities of daily living and their quality of life. The causes and mechanisms for poor thoracic mobility in these patients are complicated. The poor mobility causes respiratory parameters such as increased functional residual capacity (FRC). Thus, the degree of increase in FRC is an important indicator of the severity of COPD, and the active range of thoracic axial rotation (AROTAR) is an important parameter during routine clinical assessment of patients with COPD.

In general, adequate AROTAR is essential for sports activities such as golf, throwing, and tennis. Although movement of the vertebrae can be more accurately measured by diagnostic imaging, this is not widely used in clinical practice because of the associated cost and potential radiation exposure ${ }^{3,4)}$.

*Corresponding author. Akira Kubo (E-mail: akubo@iuhw.ac.jp)

(C2018 The Society of Physical Therapy Science. Published by IPEC Inc.

(c) (1) $\odot$ This is an open-access article distributed under the terms of the Creative Commons Attribution Non-Commercial No Deriva(CC) NC ND tives (by-nc-nd) License. (CC-BY-NC-ND 4.0: https://creativecommons.org/licenses/by-nc-nd/4.0/) 
Clinically, AROTAR has been measured by visual estimation and the use of a goniometer or inclinometer ${ }^{5,}$ ). Johnson et al. described techniques such as seated rotation technique, half-kneeling technique, and lumbar-locked rotation technique to measure AROTAR. However these positions are inapplicable in COPD patients, because they require the trunk to be in an upright position. Little has been published on the assessment of AROTAR in the supine position.

Kudo et al. ${ }^{7}$ ) reported Wing-test (W-t) as a measurement technique for the rib cage-hip joint flexibility of axial rotation in the supine position. Therefore, we considered that W-t could be used for the measurement of AROTAR in patients with COPD.

The purpose of the present study was to understand the effects of increased functional residual capacity (FRC) on AROTAR using the modified wing test ( $\mathrm{mW}$-t) to measure the rib cage-hip joint flexibility, included the influence by laterality in healthy young men. The reason for recruiting healthy young men was to exclude the bias due to general health status (malnutrition, systemic inflammation), physical activity level, quality of life, and age-related changes in physical conditions.

\section{SUBJECTS AND METHODS}

Thirty-nine right-handed healthy male volunteers (age $=21.6 \pm 1.6$ years, height $=172.9 \pm 5.9 \mathrm{~cm}$, mass $=65.7 \pm 9.4 \mathrm{~kg}$, body mass index $=21.9 \pm 2.6 \mathrm{~kg} / \mathrm{m}^{2}$ ) participated in this study. The participants were recruited from a university. Exclusion criteria were any pathologic condition of the spine, rib, shoulder, hip, or knee within the past 6 months, a history of scoliosis, or the presence of spinal deformation, and a rheumatologic or respiratory condition at the time of study. All volunteers signed an informed consent form that was approved by the institutional review board at the university of the corresponding author (Approval No. 2015-Io-6).

This study involved a descriptive laboratory design, which has been described in previous articles ${ }^{7-9)}$. Kim et al. suggested that thoraco-lumbo-pelvic rotation in supine position as leg lateral reach test and showed good reliability.

To measure AROTAR, the participant was in a supine position with both glenohumeral joints fully flexed ${ }^{8}$. In this position, one examiner stood at the cranial end and fixed both sides of scapula of the participant. One foot of the participant remained on the bed and the contralateral hip and knee joints were flexed at 90 degrees. The participant then maximally rotated his trunk to the opposite side. Another examiner measured the angle from the lines between the thigh and perpendicular to the floor (Fig. 1). A standard plastic goniometer was used to measure AROTAR. The required time was about 5 seconds after inhalation per trial. This testing position was selected because it is commonly used in the clinical setting.

The AROTAR in both right and left directions was recorded at resting expiration level (REL) and at four different FRC levels, that is, 500, 1,000, 1,500, and 2,000 $\mathrm{ml}$ air inhaled at REL from a 2,000-ml capacity rounded cylinder (ACA105, MINATO MEDICAL SCIENCE Co., Ltd, Tokyo). All AROTAR measurements were performed in a randomized order.

We modified the W-t of Kudo et al. ${ }^{7,8)}$ such that it described the results from a distance to angle. The distance from the contact surface of the back to medial surface of the thigh was changed to the angle from the lines between the thigh and

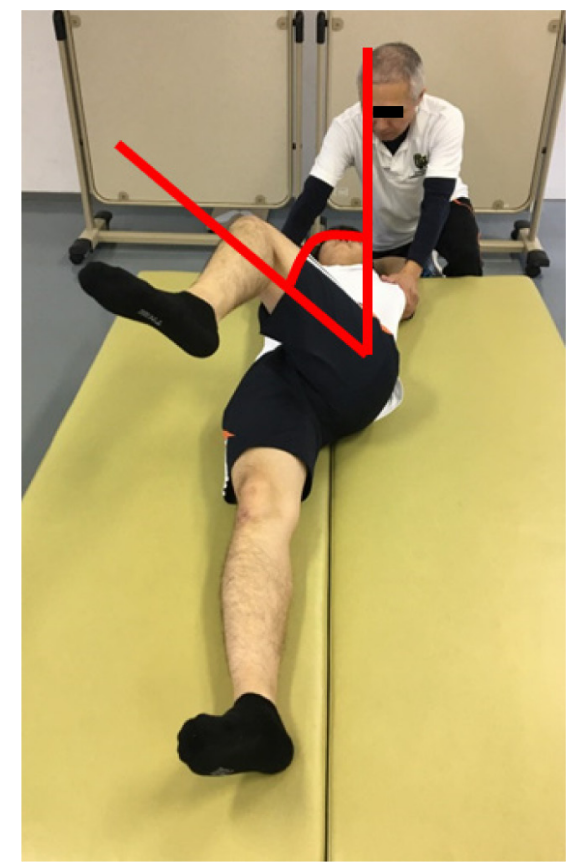

Fig.1. Measurement of the active range of thoracic axial rotation (AROTAR). 
perpendicular to the floor.

Statistical analysis of the results was carried out using SPSS for Windows 23.0 (IBM Corporation). Descriptive data are expressed as mean \pm standard deviation. The FRC level and laterality were analyzed using a two-way repeated measure of ANOVA, and post-hoc analysis was carried out using Bonferroni's method. Relationships between relative value (AROTAR for each increased FRC condition / REL AROTAR $\times 100)$ and AROTAR for each increased FRC condition were analyzed using Pearson's correlation coefficient. $\mathrm{P}<0.05$ indicated statistical significance.

\section{RESULTS}

The AROTARs of both sides under the five circumstances are shown in Table 1. A significant effect was found in only FRC factor and no significant interaction was found in other condition.

The AROTAR was significantly decreased for FRCs of 500, 1,000, 1,500, and 2,000 ml compared to REL level, 1500 and 2,000 ml compared to $500 \mathrm{ml}$ level, 1,000 compared to 2,000 ml level, and 1,500 compared to 2,000 ml level.

Pearson's correlation coefficient of relative value (AROTAR for each increased FRC level/REL AROTAR $\times 100$ ) in right and left AROTAR for each increased FRC level is shown in Table 2. AROTAR at 500, 1,500 and 2,000 ml FRC, to right side had a positive correlation from weak $(\mathrm{r}=0.34, \mathrm{p}<0.05)$ to moderate $(\mathrm{r}=0.51-0.52, \mathrm{p}<0.01)$ level, with relative value and in $1,000,1,500$ and $2,000 \mathrm{ml}$ conditions to left side had a positive moderate correlation $(\mathrm{r}=0.52-0.60, \mathrm{p}<0.01)$ with relative value. The correlation coefficient was more than 0.5 for FRCs of 1,500 and 2,000 ml, on both sides.

\section{DISCUSSION}

The purpose of the present study was to understand the effect of increased FRC on AROTAR, using the mW-t as a measure of rib cage-hip joint flexibility included the influence by laterality in healthy young men. The results revealed a decrease in AROTAR with increase in FRC. As the correlation coefficient was greater than 0.5 for FRCs of 1,500 and 2,000 ml, if the AROTAR in REL is high, the reduction in AROTAR due to increased FRC would be lesser. No significant interaction was found, and there was no difference between the left and right sides. The poor mobility of trunk flexion due to the increased FRC may be limited by anatomical and physiological muscle chain. Furthermore, an expansion of the thorax by increasing of FRC leads to decreased mobility of the trunk rotation.

An increased FRC, increased muscle activity to assist respiration, and aging effects in patients with COPD, leads to poor flexibility of all body muscles and joints, including the rib cage. It is considered that these factors simultaneously affect trunk mobility. In this study, the participants were healthy young men. Thus, this is the first study to demonstrate decreased AROTAR with a quantitative increase in FRC.

French et al. ${ }^{10)}$ evaluated the inspiratory capacity (IC)/total lung capacity (TLC) ratio and its association with survival rate. Using the IC/TLC ratio of $\leq 25 \%$, as a representation of static lung hyperinflation, they were able to demonstrate that the IC/ TLC ratio correlated with the risk of death in patients with an emphysematous phenotype of COPD. The use of the IC/TLC ratio, as a single predicting variable in patients with COPD, will allow clinicians to evaluate risk stratification of patients with the emphysematous phenotype of COPD. In our study, four different volumes of inhaled air (500-2,000 ml) from REL

Table 1. AROTAR in five different conditions of both sides

\begin{tabular}{lccccc}
\hline & $\mathrm{REL}^{(2)(3)(4)(5)}$ & $500 \mathrm{ml}^{(\mathrm{l})(4)(5)}$ & $1,000 \mathrm{ml}^{(\mathrm{l})(5)}$ & $1,500 \mathrm{ml}^{(\mathrm{l})(5)}$ & $2,000 \mathrm{ml}^{(1)(2)(3)(4)}$ \\
& $(1)$ & $(2)$ & $(3)$ & $(4)$ & $(5)$ \\
\hline $\operatorname{Rt}\left(^{\circ}\right)$ & $64.4 \pm 15.2$ & $59.9 \pm 14.8$ & $59.0 \pm 13.8$ & $56.5 \pm 15.4$ & $52.7 \pm 14.5$ \\
$\operatorname{Lt}\left({ }^{\circ}\right)$ & $61.3 \pm 13.6$ & $58.2 \pm 13.3$ & $55.1 \pm 14.2$ & $54.4 \pm 14.1$ & $52.6 \pm 14.8$ \\
\hline
\end{tabular}

Data are mean \pm SD.

Superscripts indicate significant differences between the groups $(\mathrm{p}<0.05)$.

REL: resting expiration level; Rt: right; Lt: left.

Table 2. Pearson's correlation coefficient of relative value

\begin{tabular}{llllc}
\hline & $500 \mathrm{ml}$ & $1,000 \mathrm{ml}$ & $1,500 \mathrm{ml}$ & $2,000 \mathrm{ml}$ \\
\hline $\mathrm{Rt}$ & $0.34^{*}$ & 0.30 & $0.51^{* *}$ & $0.52^{* *}$ \\
$\mathrm{Lt}$ & 0.31 & $0.53^{* *}$ & $0.52^{* *}$ & $0.60^{* *}$ \\
\hline (AROTAR in each increased FRC condition / REL AROTAR $\times 100)$ with \\
items in Rt and Lt AROTAR in each increased FRC condition of 39. \\
${ }^{*} \mathrm{p}<0.05,{ }^{* *} \mathrm{p}<0.01$ based on Pearson's correlation test. \\
Rt: right; Lt: left.
\end{tabular}


were set to increase the FRC. Under these circumstances the IC/TLC ratio is decreased. However, the IC/TLC ratio was not evaluated because the measurement of IC and TLC using spirometry was not conducted in our study. This is a limitation of this study, and further research on this is necessary.

Physical therapists need tools to assess AROTAR and to monitor changes in AROTAR for effective physical therapy. Among the non-invasive methods for measuring ROM, a three-dimensional (3D) motion analysis system using stick pictures and electromagnetic tracking systems are excellent technological devices, but they are expensive and require considerable space.

On the other hand, goniometric methods are convenient and economical. These findings provide physical therapists with specific measurement criteria for clinically relevant techniques, which can be applied using simple equipment and through training.

The main limitation of this study is that all participants were healthy university male students. Future studies in a wider population, including patients with COPD, are necessary.

\section{Conflict of interest}

The authors report no conflicts of interest in this work.

\section{REFERENCES}

1) Lozano R, Naghavi M, Foreman K, et al.: Global and regional mortality from 235 causes of death for 20 age groups in 1990 and 2010 : a systematic analysis for the Global Burden of Disease Study 2010. Lancet, 2012, 380: 2095-2128. [Medline] [CrossRef]

2) Vestbo J, Hurd SS, Agustí AG, et al.: Global strategy for the diagnosis, management, and prevention of chronic obstructive pulmonary disease: GOLD executive summary. Am J Respir Crit Care Med, 2013, 187: 347-365. [Medline] [CrossRef]

3) Ho EK, Upadhyay SS, Ferris L, et al.: A comparative study of computed tomographic and plain radiographic methods to measure vertebral rotation in adolescent idiopathic scoliosis. Spine, 1992, 17: 771-774. [Medline] [CrossRef]

4) Russell GG, Raso VJ, Hill D, et al.: A comparison of four computerized methods for measuring vertebral rotation. Spine, 1990, 15: 24-27. [Medline] [CrossRef]

5) Johnson KD, Grindstaff TL: Thoracic rotation measurement techniques: clinical commentary. N Am J Sports Phys Ther, 2010, 5: 252-256. [Medline]

6) Johnson KD, Kim KM, Yu BK, et al.: Reliability of thoracic spine rotation range-of-motion measurements in healthy adults. J Athl Train, 2012, 47: 52-60. [Medline] [CrossRef]

7) Kudo H, Dakeshita T, Ozaki J, et al.: Relationship of a tightness and a spinal function. Senmon Rihabiri, 2013, 12: 1-4 (in Japanese).

8) Takeuchi Y, Kudou T, Fujita T, et al.: Effect of functional residual capacity increase on trunk rotation of healthy adults. Rigakuryoho Kagaku, 2017, 32: 473-476 (In Japanese). [CrossRef]

9) Kim SH, Kwon OY, Park KN, et al.: Leg lateral reach test: the reliability and correlation with thoraco-lumbo-pelvic rotation range. J Sci Med Sport, 2017, 20: 2-5. [Medline] [CrossRef]

10) French A, Balfe D, Mirocha JM, et al.: The inspiratory capacity/total lung capacity ratio as a predictor of survival in an emphysematous phenotype of chronic obstructive pulmonary disease. Int J Chron Obstruct Pulmon Dis, 2015, 10: 1305-1312. [Medline] 